\title{
Experience of low dose magnesium Sulphate for the management of Eclampsia and its comparison with Pritchard regime
}

\author{
Suman $\mathbf{S}^{1}$, Jain $\mathbf{P}^{2}$, Mishra M.G ${ }^{3}$ \\ ${ }^{1}$ Dr Supriya Suman, Junior Resident, Department of Obstetrics \& Gynecology, F.H. Medical College \& Hospital, Tundla, \\ Firozabad (U.P.), ${ }^{2}$ Dr Prerna Jain, Assistant Professor, Department of Obstetrics \& Gynecology, F.H. Medical College \& \\ Hospital, Tundla, Firozabad, (U.P.), ${ }^{3}$ Dr Manju Gita Mishra, Chief Consultant, M.G.M Hospital \& Research Center, \\ Patna, Bihar, India.
}

Address for Correspondence: Dr Prerna Jain, Email: drpjaiims@ gmail.com

\begin{abstract}
Objectives: To study the effectiveness, side effects, maternal and perinatal outcome, using low dose Magnesium sulphate and to compare the results with Pritchard regime. Methods: Thirty women with eclampsia aged between 25 to 35 years were prospectively studied over two years at M.G.M hospital \& research center, Patna, Bihar. Study was designed into Group A who received low dose magnesium sulphate regime $(n=15)$ and Group B who received standard Pritchard regime $(n=15)$. Results: Groups were compared with respect to type of eclampsia, amount of dose of Magnesium sulphate and Signs of Toxicity of Magnesium sulphate. Magnesium sulphate received was 23gm in Group A and 44 gms in Group B and dose related toxicity was less in Group A. Perinatal morbidity and mortality was higher with Pritchard regime compared to low dose Magnesium sulphate regime. Conclusion: Low dose Magnesium sulphate is as effective as conventional full dose Pritchard regime with lesser side effects with equally good perinatal outcome.
\end{abstract}

Key words: Pritchard regime, Eclampsia, Magnesium sulphate

\section{Introduction}

Eclampsia remains a significant cause of maternal mortality and morbidity, worldwide [1], with studies indicating that it accounts for more than 50,000 maternal deaths, each year $[1,2]$. Because eclamptic convulsions are grave emergencies requiring proper medical treatment [2,3], the vast majority of these deaths occur in developing countries wherein the quality of maternity care can be inadequate [4]. The incidence of Eclampsia in India varies from 0.5 to $1.8 \%$ [5].

Magnesium sulphate is the anti-convulsant drug of choice for both prevention and treatment of eclampsia, but its dose-relative toxicity is of great concern [6,7]. Potential hazards include maternal hypotension, respiratory depression, and respiratory arrest (with cardiac arrest as a rare outcome) [8, 9]. Undue apprehension concerning these hazards results in

Manuscript received $4^{\text {th }}$ August 2016

Reviewed: $14^{\text {th }}$ August 2016

Author Corrected: $25^{\text {th }}$ August 2016

Accepted for Publication $12^{\text {th }}$ September 2016 limited use of the drug in many low-income countries $[10,11]$.

Varying magnesium sulphate dose protocols have been implemented to treat eclampsia, amongst which the Pritchard regime is most widely used [12]. Flower et al adjusted doses of magnesium sulphate according to body weight, plasma level and urinary excretion of magnesium sulphate [13], while Sardesai Suman et al employed a low-dose magnesium sulphate regime in eclampsia in Indian woman, finding it to be both safe and very effective [14].

The lower dosage had been chosen primarily because of the relatively small size of Indian women and concerns about toxicity in circumstances wherein there is no facility for measuring of serum levels of magnesium. It is appropriate to consider the body weight of Asian women, whose body weight is usually less than $70 \mathrm{~kg}$ [15], and if a woman is or appears to be small or of low body weight, the dose may need to be limited [15]. 
Therefore, the low dose magnesium sulphate regime that has been proposed in this study is justified.

The aim of the present study was to evaluate the efficacy of low dose magnesium sulphate in the control of convulsions in eclampsia, to assess the magnesium related toxicity, to analyze the maternal and perinatal outcomes, and to compare the results with those of the standard Pritchard regime.

\section{Material and Methods}

This study was carried out over a period of two years in the department of obstetrics and gynecology at M.G.M hospital \& research center, Patna. Thirty cases of eclampsia, either antepartum or intrapartum, were selected randomly. Patients who presented with complications like cerebro-vascular accident, renal failure, aspiration pneumonitis and HELLP syndrome; those who were deeply unconscious with cerebrovascular accident, renal failure, associated pulmonary edema, disseminated intravascular coagulation, shock and post partum eclampsia and those who had received anticonvulsant treatment before admission to the hospital were excluded from the study. Written informed consent was obtained for every case included in the study. As informed written consent requires a sound mind, in cases where patients were unconscious or confused, consent was obtained from the next of kin, usually the husband. The standard principles of managing eclampsia were followed. All patients in the study were sub-divided into two groups.

Group A: consisted of fifteen women with eclampia who received a low dose magnesium sulphate regime between March 2014 and February 2015, aged between 25-35 years, with a mean height of $151+7 \mathrm{cms}$, mean weight of $41.7+1.5 \mathrm{~kg}$, and a body mass index of 21 . Ninety percent of these patients were primigravid. The low dose regime consisted of the following: a loading dose of $3 \mathrm{gm}$ magnesium sulphate intravenously plus $2.5 \mathrm{gms}$ magnesium sulphate injection in each buttock (for a total of $8 \mathrm{gm}$ of intravenous magnesium sulphate), followed by a maintainance dose of $2.5 \mathrm{gm}$ administered intramuscularly every four hours, alternately in each buttock, over the 24 hours that followed the last seizure. (Total dose- 23gms of magnesium sulphate).

Group B: consisted of fifteen women with eclampsia who received the standard Pritchard regime between March, 2013 to February, 2014, aged 25-35 with an average body mass index of 21.5. The Pritchard regime consisted of a loading dose of $4 \mathrm{~g}$ magnesium sulphate intravenously plus $5 \mathrm{gms}$ intramuscular injection in each buttock (for a total of $14 \mathrm{gm}$ of intravenous magnesium sulphate), followed by a maintenance dose of $5 \mathrm{gms}$ intramuscular injection every 4 hours, alternately in each buttock, over the 24 hours that followed the last seizure (Total dose - 44gms of magnesium sulphate).

Patients were monitored every hour for vitals, knee jerks and urinary output. For each dose of magnesium sulphate, knee jerks should be present, respiratory rate should be more than 16 per minute, and urinary output should be more than $30 \mathrm{ml} / \mathrm{hr}$. If there was recurrence of convulsions 30 minutes after the initial loading dose, an additional $2 \mathrm{gms}$ of magnesium sulphate was given intra-muscularly. The efficacy of the low dose magnesium sulphate regime was assessed by the control of convulsions with a low dose protocol and by noting the total quantity of magnesium sulphate required for control of convulsions. A structured form was filled out for each patient with eclampsia, and maternal and perinatal events included in the form were the frequency of seizures, onset of labour, mode of delivery and perinatal outcome. Each patient's records were followed up on throughout the course of treatment.

\section{Results}

It was observed that $90 \%$ of cases of eclampsia were unbooked, aged between 25 and 35 years, and that $90 \%$ of patients were primigravida. During this prospective study, following results were found:

Table 1: Incidence of Eclampsia.

\begin{tabular}{|c|c|c|c|c|}
\hline Type of eclampsia & \multicolumn{2}{|c|}{ Group A } & \multicolumn{2}{c|}{ Group B } \\
\hline & (cases) & \% & (control) & \% \\
\hline Ante-partum & 11 & $70 \%$ & 12 & $80 \%$ \\
\hline Intra-partum & 4 & $30 \%$ & 3 & $20 \%$ \\
\hline Total & $\mathbf{1 5}$ & $\mathbf{1 0 0 \%}$ & $\mathbf{1 5}$ & $\mathbf{1 0 0 \%}$ \\
\hline
\end{tabular}


The incidence of antepartum eclampsia in group A was $70 \%$, while in group B, it was $80 \%$, and the remaining patients had intra-partum onset of eclampsia (Table I).

Table 2: Complications during Magnesium Sulphate Therapy.

\begin{tabular}{|c|c|c|c|c|}
\hline \multirow{2}{*}{ Type of complication } & \multicolumn{2}{|c|}{ Group A } & \multicolumn{2}{|c|}{ Group B } \\
\cline { 2 - 5 } & No. of Patient & $(\%)$ & No. of Patient & $(20 \%)$ \\
\hline Loss of knee jerk & 1 & $(6.67 \%)$ & 3 & $(6.67 \%)$ \\
\hline Respiratory depression & 1 & $(6.67 \%)$ & 1 & $(13.33 \%)$ \\
\hline Recurrence of fit & 0 & $(0 \%)$ & 2 & $(\%)$ \\
\hline
\end{tabular}

In the present study, we also observed that complications during magnesium sulphate therapy were fewer in Group A than Group B, and that there was no evidence of recurrence of seizures in Group A patients (Table II).

Table 3: Perinatal Outcome.

\begin{tabular}{|c|c|c|}
\hline Perinatal outcome & Group A & Group B \\
\hline Still birth & $1(6.67 \%)$ & $2(13.33 \%)$ \\
\hline Apgar score & $7-8$ & $3(20 \%)$ \\
\hline Deceleration in CTG & $1(6.67 \%)$ & $12(80 \%)$ \\
\hline Cesarean section & $7(46.67 \%)$ & $3(20 \%)$ \\
\hline Vaginal delivery & $8(53.33 \%)$ & \\
\hline
\end{tabular}

(CTG: Cardiotocogarphy)

It was observed that the incidence of still birth was $6.67 \%$ in Group A compared to $13.33 \%$ in Group B. One patient showed deceleration on CTG in Group A while three patients showed deceleration in Group B. The incidence of cesarean section and vaginal delivery was $46.67 \%$ and $53.33 \%$, respectively, in Group A compared to $80 \%$ cesarean section and $20 \%$ vaginal delivery in Group B. In Group A, the incidence of still birth, deceleration on CTG, and cesarean deliveries were comparatively fewer than in Group B, which received the standard Pritchard Regime (Table III).

The serum magnesium levels were monitored in all cases for evidence of toxicity. The mean serum magnesium value ranged between 2.78 and $3.05 \mathrm{meq} / \mathrm{lit}$ during a low dose regime. There was no evidence of toxicity in any case. In the present study, the total dose of magnesium sulphate was $23 \mathrm{gms}$, which is $52 \%$ less than what is required in the Pritchard regime.

Thus, it was observed that a low dose magnesium sulphate regime was sufficient to control eclamptic convulsions, and there was no maternal mortality due to eclampsia or its complications in the present study.

\section{Discussion}

Antenatal care has been recognized as a way to improve health outcomes for pregnant women and their babies. In the present study, it was seen that $90 \%$ of the patients were not booked. In 1952, Helmin reported that eclampsia would be scarcity if good and regular antenatal care were made available [16], whereas Mudaliar \& Menon [17] and Dawn [18] stated that 75\% of the cases were seen among primigravidas. Similar observations were made in our present study. $90 \%$ of the patients with convulsions were controlled with the use of low dose magnesium sulphate in their large study done by Sardesai et al [14]. Rashida Begum et al reported that $98 \%$ of the cases were controlled with the modified low dose Dhaka regime of magnesium sulphate [10]. The results of the study made, were comparable with these studies regarding low dose regime for the control of eclamptic convulsions.

Maternal mortality in the present study was Nil. Saedesai Suman [14] reported that maternal mortality was $2.63 \%$ with low dose regime, whereas with the Pritchard regime maternal mortality was $3.8 \%$ and $5.2 \%$ by the collaborative eclampsia trial [6]. The adverse effects of magnesium sulphate were almost rubbed out 
and seizure recurrence and maternal mortality were satisfying. The dose adjustment stems from the simple course of thought that the weight of Indian women is approximately $2 / 3^{\text {rd }}$ that of their US counterparts $(45 \mathrm{~kg}$ $\mathrm{v} / \mathrm{s} 65 \mathrm{~kg}$ ) [17], thus require a dose modification.

We received a large number of patients at M.G.M hospital \& research center who had not been administered magnesium sulphate and were sent to us directly from a referral hospital. The reasons for referral and general difficulty in managing eclampsia at referring hospitals in rural areas are often the lack of a full time obstetrician, blood bank, emergency operating room, essential life saving drugs, intravenous fluids, plasma expanders and ultrasonograms.

The study result has 3 major considerations. First is that magnesium toxicity was effectively eliminated and thus safety of the drug was increased, second is that overall cost of treatment was lowered as the lower drug dose was given to the patient [18, 19] and Magnesium sulphate is likely to become acceptable at peripheral health centre where risk of toxicity with the drug act as impediment and proves to be stumbling block.

Magnesium is a prototypical drug, with rapid onset of action, non sedative effects on the mother and baby, with good safety margin and promptly available antidote in the form of calcium gluconate. Magnesium curtails the risk of recurrent seizures compared to the other recognized drugs like diazepam and phenytoin [6]. Furthermore, Magnesium sulphate does not appear to have any prejudicial effects on the neonate $[20,21]$. Mean serum magnesium levels were taken into consideration and it was seen that level of serum magnesium remained below the therapeutic range of magnesium; which account to control convulsions. The mean serum magnesium level was ranging between 2.78-3.05 meq/lit during the low dose regime. Thus, it can be stated that low dose regime as seen in present study, was found to be free from the hazards of hypermagnesemia.

Low rate of fatality can be accredited to various factors, including the development of integrated clearly written guidelines that was first made available and then enforced. Education and training were given to all grades of staff which included hospital interns and feedback was requested. The instructions and various protocols were followed strictly and regularly clinical audits of maternal death were carried out.

\section{Conclusion}

Low dose magnesium sulphate was efficient in the control of eclamptic convulsions. The dose needed for the control of convulsion with our low dose regime was $52 \%$ less than that of Pritchard regime. It is privileged to state that there was no magnesium related toxicity; so this low dose magnesium sulphate regime as taken in our studies, suits low income and developing countries like India with both constrained and limited resources and women of lower body weight.

\section{Funding: Nil, Conflict of interest: None. Permission of IRB: Yes}

\section{References}

1. Duley L, Matar HE, Almerie MQ, Hall DR. Alternative magnesium sulphate regimes for women with pre-eclampsia and eclampsia. Cochrane Database System rev2010(8): CD00738.

2. Duley L. Maternal mortality associated with hypertensive disorders of pregnancy in Africa, Asia, Latin America and the Caribbean. Br J Obstet Gynaecol. 1992 Jul;99(7):547-53.

3. Shamsuddin L, Nahar K, Nasrin B, Nahar S, Tamanna S, Kabir RM et al. Use of parenteral magnesium sulphate in eclampsia and severe preeclampsia cases in a rural set up of Bangladesh. Bangladesh Med ResCouncBull.2005;31(2):75-82.

4. Mayes M, Sweet BR, Tiran D: Maye's Midwifery- A textbook for Midwives London, Bailliere Tindall, 1997, pp 533-545.

5. Bhargava A, Pant R, Chutani I, Singh SK : In search for accelerated recovery from eclampsia. J Obstet Gynecol India 2006; 56:402-405.

6. Which anticonvulsant for women with eclampsia? Evidence from the Collaborative Eclampsia Trial. Lancet 1995:345 (8963):1455-63.

7. Shilva, Saha SC, Kalra J, Prasad R. Safety and efficancy of low dose Magnesium sulphate in the treatment of Eclampsia. Int J Gynaecol Obstet. 2007 May;97(2):150-1. Epub 2007 Mar 21.

8. Witlin AG. Prevention and treatment of eclamptic convulsions. Clin Obstet gnyecol 1999; 42 (3) : 507-18. 
9. Idama TO, Lindow SW. Magnesium sulphate: a review of clinical pharmacology applied to obstetrics. Br J Obstet Gynecol1998;105(3):260-8.

10. Begum R, Begum A, Johanson R, Ali MN, Akhter S. A low dose ("Dhaka") magnesium sulphate regime for eclampsia. Acta Obstet Gynecol Scand. 2001; 80 (11): 998-1002.

11. Mahajan NN, Thomos A, Soni RN, Gaikwad NL, Jain SM. 'Padhar Regime' - a low dose magnesium sulphate treatment for eclampsia. Gynecol Obstet Invest. 2009;67(1):20-4. doi: 10.1159/000158647. Epub 2008 Sep 30.

12. Pritchard JA. The use of magnesium ion in the management of eclamptogenic toxemias. Surg Gynecol Obstet. 1955 Feb;100(2):131-40.

13. Flower CA. Magnesium sulphate in toxemia of pregnancy-New dosage schedule based on body weight. Obstet Gynecol. 1962 Mar;19:315-27.

14. Sardesai S, Maira S, Patil A et al. Low dose Magnesium Sulphate therapy for eclampsia and imminent eclampsia Regime tailored for indian women. J Obstet Gynecol India 2003; 53-6:546-550.

15. Phusapradit W, Saropala N, Haruvasin S, Thuvasethakul P. Serum level of magnesium attained in magnesium sulphate therapy for severe preeclampsia. Asia Oceania J Obstet Gynecol. 1993; 19(4): 387-90.

16. Helmin RHJ. Prevention of eclampsia and preeclampsia. Lancet. 1952; 1:64-8.

17. Maternal anthropometry and pregnancy outcomes. A WHO Collaborative Study. Bull world Health Organ. 1995; 73 (Suppl): 1-98.

18. El-Nafaty AU, Melah GS, Massa AA, Audu BM, Nelda M. The analysis of eclamptic morbidity and mortality in the specialist Hospital Gombe, Nigeria. J Obstet Gynocol. 2004;24 (2): $142-7$.

19. Ekele BA, Ahmed Y. Magnesium sulfate regimens for eclampsia. Int J Gynecol Obstet. 2004; 87(2): 149-50.

20. Guzman ER, Conley M, Stewart R, Ivan J, Pitter M, Kappy K. Phenytoin and magnesium sulphate effects on fetal heart rate tracing assessed by computer analysis. Obstet Gynecol. 1993; 82 (3):375-379.

21. Atkinson MW, Belfort MA, Sadde GR, Moise KJ. The relation between magnesium sulphate therapy and fetal heart rate variability.Obstet Gynecol1994;83:967-70.

\section{How to cite this article?}

Suman S, Jain P, Mishra M.G. Experience of low dose magnesium Sulphate for the management of Eclampsia and its comparison with Pritchard regime. Int J Med Res Rev 2016;4(11):1935-1939.doi:10.17511/ijmrr. 2016.i11.04. 